\title{
Evaluación de subproductos de Solanum tuberosum y Daucus carota mediante FES como alternativa en la alimentación animal
}

\section{Evaluation of byproducts of Solanum tuberosum and Daucus carota by FES}

\section{as an alternative in animal feed}

\author{
Nidia Lorena Caro Cusba' \\ Gabriel Fernando Saavedra Montañez ${ }^{2}$ \\ Luis Miguel Borras Sandoval ${ }^{3}$
}

DOI: https://doi.org/10.19053/01228420.v18.n2.2021.12502

RESUMEN: La creciente demanda de alimentos como maíz o soya ha favorecido la implementación de biotecnologías por medio del aprovechamiento de residuos agroindustriales con el fin de obtener dietas alternativas con alto valor biológico. Por esta razón, el objetivo de esta investigación fue elaborar una dieta a base de subproductos de cosecha de papa Solanum tuberosum y zanahoria Daucus carota tratados mediante Fermentación en Estado Sólido (FES). Se realizó análisis de calidad postcosecha, posteriormente, se mezclaron en proporción de $15 \%$ junto con palmiste (20\%), cema de trigo (20\%), torta de soya (10\%), maíz (10\%), cascarilla de café (5\%), melaza (4\%) y aditamentos como premezcla vitamínica $(0,5 \%)$ e inoculante bacteriano $(0,5 \%)$. A continuación, el alimento preparado se sometió a FES y se evalúo por medio de análisis composicional y microbiológico. Se realizó análisis estadístico descriptivo de las variables evaluadas y se obtuvo valores de MS de 66,7\%, humedad $33,3 \%$, proteína bruta $19,4 \%$, cenizas $5,21 \%$, extracto etéreo $6,35 \%$ y fibra cruda $16,9 \%$. El análisis microbiológico determinó que el recuento de mesófilos aerobios fue mayor exponencialmente a las 48 horas respecto de las 72 horas $(110,67 \pm 23,44)$, no se observó crecimiento de mohos y levaduras a las 48 horas y a las 72 horas se reportaron $(14,67 \mathrm{UFC} / \mathrm{g} \pm 5,03)$. Se concluye que mediante el uso de FES se puede incrementar el valor biológico de la papa y zanahoria en mezcla con otras materias primas para la obtención de dietas destinadas a la alimentación animal.

PALABRAS CLAVE: Alimento, fermentación, microbiología, nutrición animal, proteína
ABSTRACT: The growing demand for foods such as corn or soybeans has favored the implementation of biotechnologies through the use of agro-industrial waste in order to obtain alternative diets with high biological value. For this reason, the objective of this research was to develop a diet based on harvest by-products of potato Solanum tuberosum and carrot Daucus carota treated by Solid State Fermentation (FES). Postharvest quality analysis was carried out, subsequently, they were mixed in a proportion of $15 \%$ together with palm kernel $(20 \%)$, wheat ceme $(20 \%)$, soybean cake $(10 \%)$, corn $(10 \%)$, coffee husk (5\%), molasses (4\%) and additives such as vitamin premix $(0.5 \%)$ and bacterial inoculant $(0.5 \%)$. The prepared food was then subjected to FES and evaluated by compositional and microbiological analysis. Descriptive statistical analysis of the evaluated variables was performed and DM values of $66.7 \%$, humidity $33.3 \%$, crude protein $19.4 \%$, ash $5.21 \%$, ether extract $6.35 \%$ and crude fiber $16,9 \%$ were obtained. The microbiological analysis determined that the aerobic mesophil count was exponentially higher at 48 hours compared to 72 hours $(110.67 \pm 23.44)$, no growth of molds and yeasts was observed at 48 hours and at 72 hours they were reported (14.67 CFU / $\mathrm{g} \pm 5.03$ ). It is concluded that by using FES the biological value of potatoes and carrots can be increased in a mixture with other raw materials to obtain diets intended for animal feed.

ADDITIONAL KEY WORDS: Food, fermentation, microbiology, animal nutrition, protein. 


\section{Introducción}

El incremento de la población mundial y con ello el aumento de la demanda de alimentos y fuentes de proteína para la alimentación humana, han generado insuficiencia en los suministros de materias primas para la fabricación de alimentos balanceados ocasionando un aumento en los costos en la producción pecuaria, donde se ha establecido que la alimentación representa el $70 \%$ de los costos de producción (Castillo-Badilla et al., 2019). Por esta razón, la implementación de biotecnologías en la alimentación animal ha permitido la obtención de dietas con alto valor biológico, fácil acceso a menor costo especialmente en pequeños y medianos productores (de Araújo Sousa \& Correia, 2010; FAO, 2016). Así pues, el aprovechamiento de subproductos agrícolas o de cosecha a través de procesos como FES permite mediante la acción de microrganismos la obtención de alimentos energético-proteicos, mejorando sus características físicas y de conservación (De Araújo \& Correia, 2010), cuando se someten a determinadas condiciones de $\mathrm{pH}$, humedad, aireación y temperatura (Borrás-Sandoval \& Torres-Vidales, 2016), considerándose una fuente importante de biomasa en la alimentación animal (Prada, 2012).

El departamento de Boyacá se destaca en la producción agrícola del país, especialmente con la producción de tubérculos de Solanum tuberosum y hortalizas como Daucus carota L., siendo uno de los principales productores de zanahoria en Colombia, donde registró para el año 2018 una cifra récord de 6.669 ha sembradas (DANE, 2018). Paralelamente, la producción de papa en Boyacá en 2018 representó el 27\% del área sembrada nacional de un total de 74.885 ha sembradas en todo el país (DANE, 2018). Bajo este contexto, se estima que en Colombia se pierde y desperdicia el 34\% de los alimentos producidos siendo una alternativa de aprovechamiento con gran potencial con fines a la alimentación animal (Ajila et al., 2012; FAO, 2016).

La papa se caracteriza por ser un alimento rico en carbohidratos, carotenos y ácido ascórbico, posee un alto contenido de humedad alrededor del $70 \%$, no contiene grasas y un bajo contenido de proteína alrededor del 2-3\%. La zanahoria se caracteriza por ser rica en carotenos, vitaminas del complejo $B$, vitamina A, E, potasio, fosforo, magnesio, yodo y calcio. Tanto papa como zanahoria, en estado fresco son bajos en contenido nutricional, razón por la cual se desea evaluar su desempeño al mezclarse con palmiste, cema de trigo, torta de soya, maíz, cascarilla de café y melaza a través de la acción de microorganismos fermentadores con el objetivo de determinar su potencial en la nutrición animal. 


\section{Materiales y Métodos}

\section{Ubicación geográfica}

Los procedimientos analíticos de las materias primas Solanum tuberosum y Daucus carota, así como del alimento preparado se llevaron a cabo en el laboratorio de fisiología vegetal y laboratorio de nutrición animal de la Universidad Pedagógica y Tecnológica de Colombia (UPTC), Tunja - Boyacá.

\section{Muestra}

Los ingredientes papa y zanahoria fueron adquiridos de forma comercial en centros de acopio locales del municipio de Tibasosa, Boyacá. Posteriormente, fueron lavadas y picadas a un tamaño aproximado de 5 milímetros $(\mathrm{mm})$. Se realizó caracterización de calidad post cosecha, se evaluó firmeza, pH, sólidos solubles totales ('grados Brix) y acidez titulable (Tabla I). Además, se determinó firmeza del material vegetal $(\mathrm{N})$ por medio de penetrómetro digital (PCE-PTR200, Tunja) con aproximación 0,05 N. Sólidos solubles totales (SST) se determinó a través de mediciones de grados Brix con un refractómetro digital (Hanna ${ }^{\circledR}$, Tunja) de rango 0 a $85 \%$ con precisión $0,1^{\circ}$ Brix. pH se determinó tomando 1 mililitro $(\mathrm{mL})$ de sustrato producto del macerado del material vegetal previamente mezclado y medido con un potenciómetro previamente calibrado con soluciones buffer de $\mathrm{pH}$ 7,0. Acidez titulable (ATT) se midió utilizando $1 \mathrm{~mL}$ de sustrato al cual se le adicionó 3 gotas de fenoftaleína en una titulación potenciométrica hasta pH de 8,2.

TABLA I. Caracterización fisicoquímica de Solanum tuberosum y Daucus carota.

\begin{tabular}{|l|c|c|}
\cline { 2 - 3 } \multicolumn{1}{c|}{} & \multicolumn{2}{c|}{ Muestras } \\
\cline { 2 - 3 } \multicolumn{1}{c|}{} & Solanum tuberosum & Daucus carota \\
\hline Firmeza & $70,69 \pm 9,98$ & $66,45 \pm 7,44$ \\
\hline $\mathrm{pH}$ & $5,84 \pm 0,24$ & $6,00 \pm 0,11$ \\
\hline Solidos solubles ('Brix) & $6,08 \pm 1,02$ & $3,8 \pm 0,32$ \\
\hline Acidez titulable (\% Ac. Ascórbico) & $0,19 \pm 0,04$ & $0,45 \pm 0,07$ \\
\hline
\end{tabular}

\section{Preparación del alimento}

Se utilizó un inóculo bacteriano a base de bacterias acido lácticas hetero fermentativas desarrollado bajo la metodología (Borras-Sandoval et al., 2015) utilizando cultivo comercial Liofast Y452B, SACCO ${ }^{\circledR}$ (Tabla II). Se elaboró una dieta a base de la mezcla de papa (15\%) y zanahoria (15\%), se agregó materiales secantes como palmiste (20\%), cema de trigo (20\%), torta de soya (10\%), maíz (10\%), cascarilla de café (5\%), melaza (4\%), aditamentos y minerales $(0,5 \%)$ e inoculo bacteriano $(0,5 \%)$ (Tabla III) de tal manera que la dieta 
fuera isoproteíca e isoenergética según tablas del National Research Council (NRC, 2012).

TABLA II. Componentes del preparado microbiano con actividad ácido láctica.

\begin{tabular}{|l|l|}
\hline Componentes del preparado microbiano & Aportes de los componentes \\
\hline Melaza & Fuente de azúcares fermentables \\
\hline Harina de maíz & Fuente de energía \\
\hline Harina de frijol & Fuente de proteína \\
\hline Urea & Fuente de NNP para la fermentación \\
\hline Sulfato de magnesio & Fuente de azufre \\
\hline Premezcla mineral (Bovinos) & Fuente de elementos inorgánicos y minerales \\
\hline Inóculo (Yogurt) & Fuente de BAL \\
\hline Agua & Solvente del sistema \\
\hline
\end{tabular}

$\mathrm{NNP}=$ Nitrógeno no proteico; $\mathrm{BAL}=$ Bacterias con actividad acido láctica.

Fuente: (Borrás-Sandoval et al., 2017)

Los ingredientes se mezclaron hasta obtener un alimento uniforme, se preparó un total de $60 \mathrm{~kg}$ y se conservaron en bolsas selladas no herméticamente con capacidad de $20 \mathrm{~kg}$ a temperatura y humedad constante de $17{ }^{\circ} \mathrm{C}$ durante 72 horas. Se tomó una muestra que fue sometida a evaluación nutricional determinando materia seca, humedad, cenizas, fibra cruda, proteína bruta, extracto etéreo, fibra en detergente neutro, fibra en detergente acido, extracto no nitrogenado, nitrógeno, calcio y fosforo, además de análisis microbiológico.

TABLA III. Composición porcentual del alimento preparado.

\begin{tabular}{|l|c|}
\hline Materia prima & Inclusion(\%) \\
\hline Daucus carota & 15 \\
\hline Solanum tuberosum & 15 \\
\hline Palmiste & 20 \\
\hline Cema de trigo & 20 \\
\hline Torta de soya & 10 \\
\hline Maiz & 10 \\
\hline Cascarilla de café & 5 \\
\hline Melaza & 4 \\
\hline Premezcla vitamínica & 0,5 \\
\hline Inoculante & 0,5 \\
\hline Total & 100 \\
\hline
\end{tabular}




\section{Análisis composicional}

Se determinó el contenido de materia seca, humedad y ceniza se determinó por análisis gravimétrico. La proteína bruta se determinó por método de Kjeldahl, se utilizó éter para el extracto etéreo y análisis por gravimetría, fibra detergente cruda, fibra en detergente acida y fibra en detergente neutro por método de Van Soest (Van Soest et al., 1991), se realizó análisis composicional de los ingredientes (Tabla IV).

TABLA IV. Análisis composicional de los principales ingredientes.

\begin{tabular}{|l|c|c|c|c|c|c|c|c|}
\hline \multirow{2}{*}{ INGREDIENTE } & Húmedad & MS & Ceniza & PB & EE & FC & FDN & FDA \\
\cline { 2 - 9 } & $\mathbf{( \% )}$ & $\mathbf{( \% )}$ & $\mathbf{( \% )}$ & $\mathbf{( \% )}$ & $\mathbf{( \% )}$ & $\mathbf{( \% )}$ & $\mathbf{( \% )}$ & $\mathbf{( \% )}$ \\
\hline Solanum tuberosum & 35 & 65 & 8 & 7 & 0,5 & 15 & 7 & 2,9 \\
\hline Daucus carota & 21,7 & 78,3 & 5,1 & 1,4 & 7,1 & 8,2 & 55,9 & 19,5 \\
\hline Harina de palmiste & 9,8 & 90,2 & 4,5 & 16,3 & 1,8 & 20,2 & 63,8 & 40,2 \\
\hline Cema de trigo & 10,0 & 90 & 1,6 & 13,8 & 2,0 & 2,9 & 11,9 & 3,9 \\
\hline Torta de soya & 12 & 88 & 6,2 & 44 & 1,9 & 5,9 & 12,8 & 7,2 \\
\hline Maíz & 12 & 88 & 8 & 9 & 8 & 14 & 19,3 & 5,8 \\
\hline Cascarilla de café & 7,2 & 92,8 & 0,5 & 5,6 & 1,3 & 17,8 & 79,4 & 13,5 \\
\hline
\end{tabular}

H: húmedad; MS: materia seca; Ceniza; PB: proteína bruta; EE: extracto etéreo; FC: fibra cruda; FDN: fibra en detergente neutro; FDA: fibra en detergente ácida.

Fuente: Autor

\section{Análisis microbiológico}

Se realizó 48 horas y 72 horas después de la elaboración del producto final. Se utilizó el método recuento en placa NTC 4092 utilizando dilución $10^{-6}$, el cultivo se realizó con los procedimientos Compact Dry para Mesófilos Aerobios $^{\circledR}$ (UFC/g), mohos y levaduras ${ }^{\circledast}$ (UFC/g), incubados a $37^{\circ} \mathrm{C}$ por 48 horas después de las 72 horas de fermentación de las dietas.

\section{Análisis estadístico}

Los datos obtenidos del análisis composicional del alimento fes papa-zanahoria, así como el análisis microbiológico fueron ordenados en una hoja de cálculo de Microsoft Excel mediante la aplicación de estadística descriptiva y paquete estadístico SPSS Stadistics versión 19. 


\section{Resultados y Discusión}

\section{Humedad y materia seca}

El alimento preparado presentó una humedad de 33,3\% y contenido en base materia seca fue de 66,7\% (Tabla V). Resultados similares obtenidos por (Saavedra Montañez et al., 2018), donde se sometió a fermentación dietas con porcentajes de inclusión de papa y zanahoria de $30 \%$ y se obtuvo valores de humedad a las 48 horas de $36.33 \%$ y $37.82 \%$ respectivamente permitiendo así una adecuada fermentación y condiciones óptimas para el crecimiento de los microorganismos. Por otra parte, difieren con lo obtenido por (Borras-Sandoval et al., 2014), donde se elaboraron productos FES con $90 \%$ de inclusión de papa en la dieta sometiéndolos a fermentación a 20,25 y $30^{\circ} \mathrm{C}$ y se obtuvo valores de humedad entre $61,4-80,7 \%$ a las 24 horas y posteriormente incrementaron $61,8-82,0 \%$.

\section{Proteína bruta}

Se obtuvo un valor de proteína de $19,4 \%$ en el alimento preparado fes papa-zanahoria (ver Tabla V). El análisis composicional de los ingredientes demostró que el mayor valor proteico se encontró en la torta de soya, harina de palmiste y la cema de trigo con $44,16,3$ y $13,8 \%$ PB respectivamente, lo que indica que el aumento de $\mathrm{PB}$ tras el proceso de fermentación puede otorgarse al preparado microbiano con actividad ácido láctica como acelerante biológico (Borrás et al., 2020) y a los procesos bioquímicos que se llevan a cabo mediante la degradación de una pequeña cantidad de proteínas solubles y degradables presentes que por acción de los ingredientes energéticos usados mediante proteasas de los microorganismos se degradan a péptidos como lo manifiesta (Pulido-Suárez et al., 2016) citado de (Hristov et al., 2005). En efecto, este resultado concuerda con lo reportado en productos fes con Daucus carota en inclusión del 35\% cuyo valor inicial de PB fue de 1,4\% y tras el proceso de fermentación se obtuvo $18,4 \%$ de PB en el tratamiento control, $15,2 \%$ en el FES 2 ( $\sin$ repila de trigo) y $18,3 \%$ en el FES 3 (sin cascarilla de café) (Fonseca-López \& Saavedra-Montañéz, 2018).

Por otra parte, (Rodriguez-Salgado et al., 2021) obtuvieron $27,80 \%$ en un producto fes papa-zanahoria a razón de $25 \%$ de inclusión en una dieta destinada para la alimentación de terneros, además se reportó valores de $27,51 \%$ PB con un producto fermentado con residuos agroindustriales de pera Pyrus communis (Pulido-Suárez et al., 2016). 
TABLA V. Composición química del producto FES - papa y zanahoria.

\begin{tabular}{|l|c|}
\hline Parámetro & Resultado \\
\hline Humedad (H) & $33,3 \%$ \\
\hline Materia Seca (MS) & $66,7 \%$ \\
\hline Cenizas & $5,21 \%$ \\
\hline Proteína Bruta (PB) & $19,4 \%$ \\
\hline Extracto etéreo (EE) & $6,35 \%$ \\
\hline Fibra Cruda (FC) & $16,9 \%$ \\
\hline Fibra Detergente neutro (FDN) & $42,9 \%$ \\
\hline Fibra detergente acido (FDA) & $18,9 \%$ \\
\hline Extracto no nitrogenado (ENN) & $52,1 \%$ \\
\hline Nitrógeno (N) & $3,11 \%$ \\
\hline Fósforo & $0,53 \%$ \\
\hline Calcio & $0,78 \%$ \\
\hline
\end{tabular}

Humedad; MS: materia seca; Ceniza; PB: proteína bruta; EE: extracto etéreo; FC: fibra cruda; FDN: fibra en detergente neutro; FDA: fibra en detergente ácida; FC: fibra cruda; ENN: extracto no nitrogenado; N: nitrógeno.

\section{Cenizas}

El valor obtenido de cenizas en el alimento fue de 5,21\%. Ciertamente, con la inclusión de la papa en el preparado se genera un gran aporte de cenizas ya que en crudo presento un valor de $8,0 \%$, similar al encontrado por (Fonseca-López \& Borras-Sandoval, 2014) donde se reportó un contenido de cenizas de $8,98 \%$ usado en estado fresco en la alimentación de vacas Holstein . No obstante, se debe tener en cuenta que los valores de ceniza dependen de la naturaleza del suelo donde fue cultivado el tubérculo (Borrás et al., 2020) y a la adición de 0.5 \% de premezcla mineral al sustrato para la fermentación (Miranda et al., 2018). resultado similar al obtenido en un estudio con papa en la alimentación de vacas lecheras donde se reportó un aporte de cenizas del 8,98\% (Borras-Sandoval et al., 2014).

\section{Extracto etéreo}

El valor de EE obtenido en el alimento FES papa - zanahoria fue 6,35\% (ver Tabla V). Esta variable hace referencia a los compuestos extraídas con éter etílico entre los que se encuentran las grasas brutas o lípidos y todos los esteres de los ácidos grasos incluyendo vitaminas liposolubles, fosfolípidos, carotenoides entre otros compuestos. Resultados que difieren en lo encontrado por (Willan Caicedo et al., 2019) al llevar a cabo un proceso de fes con tubérculos de taro Colocasia esculenta (L.) donde se obtuvo EE de 1,50\%.

Los resultados de EE que se obtuvieron aquí son similares a los actualmente usados en concentrados comerciales de la región para especies monogástricas. 


\section{Fibra cruda}

Se obtuvo un valor de 16,9\% (Tabla V), teniendo en cuenta que ingredientes como harina de palmiste, cascarilla de café y Solanum tuberosum presentaron $\mathrm{FC}$ de 20, 2, 17,8 y 15\% respectivamente, demostrando así, que la adición de ingredientes con valores altos de FC se relaciona directamente con el contenido de paredes celulares en relación al nivel de almidón de la materia prima utilizada (Saavedra Montañez et al., 2018) citado de (Aranda et al., 2012).

El contenido de fibra obtenido en la dieta fes papa-zanahoria es superior a los requerimientos de fibra para la animales de granja como los porcinos, debido a que ingredientes con alto contenido de fibra generan un mayor incremento de calor durante la digestión y de esta manera una mayor diferencia entre la ED y la EN si se compara con alimentos con niveles moderados de fibra en un ambiente termo neutral Por esta razón, dietas con alto de contenido de fibra no actúan en detrimento cuando especies monogástricas son sometidos a condiciones de invierno o de difícil control medioambiental en fases de crecimiento (W Caicedo et al., 2018).

\section{Análisis Microbiológico}

Se realizó análisis microbiológico por triplicado del producto final a muestras obtenidas a 48 y 72 horas después de la elaboración.

TABLA VI. Resultado del análisis microbiológico producto final.

\begin{tabular}{|l|c|c|c|c|c|c|}
\hline \multirow{2}{*}{ Análisis microbiológico } & \multicolumn{5}{|c|}{ Resultados } \\
\cline { 2 - 7 } & \multicolumn{3}{|c|}{ 48 horas } & \multicolumn{3}{c|}{72 horas } \\
\cline { 2 - 7 } & M1 & M2 & M3 & M1 & M2 & M3 \\
\hline Mesófilos aerobios (UFC/g) & $84^{*} 10^{6}$ & $120^{*} 10^{6}$ & $128^{*} 10^{6}$ & $7^{*} 10^{6}$ & $11^{*} 10^{6}$ & $5^{*} 10^{6}$ \\
\hline Mohos y levaduras (UFC/g) & 0 & 0 & 0 & 14 & 10 & 20 \\
\hline
\end{tabular}

UFC: Unidades formadoras de colonia.

El recuento de Mesófilos aerobios fue mayor exponencialmente a las 48 horas respecto de las 72 horas $(110,67 \pm 23,44)$ (ver Tabla VI), esto debido principalmente a la estabilización del pH al generarse consumo de carbohidratos para la formación de proteína microbiana tras las 72 horas (Saavedra Montañez et al., 2018). Adicionalmente, se destaca que con el aumento de mesófilos aerobios se ejerce un efecto inhibitorio de crecimiento de entero bacterias, debido principalmente a la acción ejercida por las bacterias acido lácticas demostrando que es adecuado para mantener valores de $\mathrm{pH}$ bajos y a su capacidad de producir ácido láctico y peróxido de hidrogeno (Miranda-Yuquilema et al., 2018) facilitando la eliminación de patógenos indeseables (Borrás et al., 2020). 
Las bacterias aerobias mesófilas expresan la carga total de microorganismos en presencia de oxígeno y a temperaturas que oscilan entre 15 y $45^{\circ} \mathrm{C}$, su importancia radica en que expresan la actividad microbiana total en un proceso de tipo biológico (Willan Caicedo et al., 2019).

Para el caso de los mohos y levaduras, a las 48 horas no se observó crecimiento y a las 72 horas se reportó 14,67 UFC/g \pm 5,03 (Tabla VI), que puede atribuirse a bajo contenido de nitrógeno en forma de urea en la dieta $<1 \%$ (Ajila et al, 2012), ya que concentraciones por encima del $1 \%$ de urea como fuente de nitrógeno frena su crecimiento (Fonseca-López \& Saavedra-Montañez, 2018). El resultado obtenido se encuentra dentro del rango esperado para el mantenimiento del proceso de fermentación como lo encontrado el encontrado en un preparado microbiano a base de bacterias acido lácticas (Borrás-Sandoval et al., 2017).

\section{Conclusiones}

Factores como la humedad determinan la efectividad del proceso fermentativo, en este trabajo, se observó que la papa y zanahoria en estado fresco presentaron un contenido de 35 y $21,7 \%$ respectivamente y que al mezclarse en una dieta con palmiste, cema de trigo, torta de soya, maíz y cascarilla de café se obtiene una dieta con 33,3\% de humedad limitando así el crecimiento de hongos y levaduras a las 48 horas de fermentación y estabilizándose a las 72 horas de fermentación. Así mismo, el valor proteico del producto fes papa-zanahoria incremento debido a la adición del inoculo bacteriano $(0,5 \%)$, sin adición de urea en este alimento.

El contenido de minerales en este alimento preparado fue similar a los usados en alimentos balanceados comerciales, sin embargo, en dietas donde se incluye Solanum tuberosum puede presentar variaciones debido a la variedad y tipo de suelo donde se cultive.

El contenido de fibra del producto fes papa-zanahoria fue superior a los requerimientos de fibra para animales de granja, debido al uso de ingredientes con alto contenido de fibra generan un mayor incremento de calor durante la digestión, no obstante, puede interferir con el consumo de alimento.

\section{Agradecimientos}

Los autores manifiestan su agradecimiento a la Universidad Pedagógica y Tecnológica de Colombia, al laboratorio de Nutrición Animal de la Universidad Pedagógica y Tecnológica de Colombia, Seccional Tunja y a las personas cuya colaboración fue imprescindible en la ejecución de este proyecto. 


\section{Referencias}

Ajila, C. M., Brar, S. K., Verma, M., Tyagi, R. D., Godbout, S., \& Valéro, J. R. (2012). Bio-processing of agro-byproducts to animal feed. Critical Reviews in Biotechnology, 32(4), 382-400. https://doi.org/10.3109/07388551.2012.659172

Aranda, E. M., Georgana, L. E., \& Salgado, J. A. R. S. (2012). Elaboración de un alimento basado en caña de azúcar a partir de la fermentación en estado sólido y con diferentes niveles de zeolitas. Revista Cubana de Ciencia Agrícola, 46(2), 159-163. https://www.redalyc.org/pdf/1930/193024447007.pdf

Borras-Sandoval, L. M., Iglesias, A. E., \& Moyano-bautista, M. A. (2014). Efecto de la temperatura y el tiempo sobre los indicadores de la papa (Solanum tuberosum) fermentada en estado sólido Effect of temperature and time on indicators of potato ( Solanum tuberosum ), fermented in solid state. Revista Ciencia y Agricultura, 1 1 (2), 31-38. https://dialnet.unirioja.es/servlet/articulo?codigo=5178280

Borras-Sandoval, L. M., Iglesias, A. E., \& Saavedra Montañez, G. F. (2015). Evaluación de la dinámica de conservación del producto final de un alimento obtenido por fermentación en estado sólido de la papa FES-papa. Ciencia y Agricultura, 12, 73-82. https://dialnet.unirioja.es/servlet/articulo?codigo=5321703

Borrás-Sandoval, Luis M, \& Torres-Vidales, G. (2016). Producción de alimentos para animales a través de fermentación en estado sólido - FES Producción de alimentos para animales a través de fermentación en estado sólido - FES Animal feed production by solid state fermentation - SSF Produção De Alimentos Para. Orinoquia, 20:2, 8. http://www.scielo.org.co/pdf/rori/v20n2/v20n2a07.pdf

Borrás-Sandoval, Luis Miguel, Valiño-Cabrera, E. C., \& Rodríguez-Molano, C. E. (2017). Preparado microbiano con actividad ácido láctica como acelerante biológico en los procesos de fermentación para alimento animal. Ciencia y Agricultura, 14(1), 7-13. https://doi.org/10.19053/01228420.v14.n1.2017.6083

Borrás, L. M., Valiño, E. C., Elías, A., Martínez, J. J., Sanabria, A. M., Becerra, M. L., \& Martínez, J. J. (2020). Solid-state fermentation of post- harvest wastes of Solanum tuberosum and a microbial preparation Fermentación en estado sólido de residuos poscosecha de Solanum tuberosum y un preparado microbiano. Cuban Journal of Agricultural Science,54(4), 1-10. http://scielo.sld.cu/pdf/ cjas/v54n4/2079-3480-cjas-54-04-525.pdf

Caicedo, W, Sanchez, J., Tapuy, A., Vargas, J. C., Samaniego, E., Valle, S., Moyano, J., \& Pujupat, D. (2018). Apparent digestibility of nutrients in fattening pigs ( Largewhite $x$ Duroc $x$ Pietrain ), fed with taro (Colocasia esculenta ( L .) Schott ) meal. Technical note Digestibilidad aparente de nutrientes en cerdos de ceba ( Largewhite x Duroc x Pietrain ), a. Cuban Journal of Agricultural Science, 52(2), 1-6. https://www.cjascience.com/index.php/CJAS/article/view/795

Caicedo, Willan, Moya, C., Tapuy, A., Caicedo, M., \& Perez, M. (2019). Composición química y digestibilidad aparente de tubérculos de taro procesados por fermentación en estado sólido (FES) en cerdos de crecimiento. Revista de Investigaciones Veterinarias del Perú, 30(2), 580-589. https://doi.org/10.15381/rivep. v30i2.16078

Castillo-Badilla, G., Vargas-Leitón, B., Hueckmann-Voss, F., \& Romero-Zúñiga, J. J. (2019). Factors that affect the production in first lactation of dairy cattle of Costa Rica. Agronomy Mesoamerican, 30(1), 209-227. https://doi.org/10.15517/ am.v30i1.33430 
DANE. (2018). Boletín Técnico. Encuesta nacional agropecuaria ENA. https://www. dane.gov.co/files/investigaciones/agropecuario/enda/ena/2018/boletin_ ena_2018.pdf

De Araújo Sousa, B. A., \& Correia, R. T. P. (2010). Biotechnological reuse of fruit residues as a rational strategy for agro-industrial resources. Journal of Technology Management and Innovation, 5(2), 104-1 12. https://doi.org/10.4067/ S0718-27242010000200010

FAO. (2016). Climate is changing. Food and agriculture must change. http://www. fao.org/3/i5758e/i5758e.pdf

Fonseca-López, D. A., \& Borras-Sandoval, L. M. (2014). Evaluation effect of fresh potatoes included in a food based meal, on production and milk quality in Holstein cows. 11 (c). Revista Ciencia y Agricultura 11(1), 55-65. https://www. redalyc.org/articulo.oa?id $=560058658007$

Fonseca-López, D., \& Saavedra-Montañéz, G. (2018). Elaboración de un alimento para ganado bovino a base de zanahoria (Daucus carota L.) mediante fermentación en estado sólido como una alternativa ecoeficiente Food preparation for carrot-based cattle (Daucus carota L .) using solid state fermentation fo. Revista Colombiana de Ciencias Hortícolas, 12(1), 175-182. https://revistas.uptc.edu. co/index.php/ciencias_horticolas/article/view/7416

Hristov, A. N., Ropp, J. K., Grandeen, K. L., Abedi, S., Etter, R. P., Melgar, A., \& Foley, A. E. (2005). Effect of carbohydrate source on ammonia utilization in lactating dairy cows. Journal of Animal Science, 83(2), 408-421. https://doi. org/10.2527/2005.832408x

Miranda-Yuquilema, J. E., Marin-Cárdenas, A., Sánchez-Macías, D., \& García-Hernández, Y. (2018). Obtaining, characterization and evaluation of two candidate preparations for probiotics developed with agroindustrial waste. Revista MVZ Cordoba, 23(1), 6487-6499. https://doi.org/10.21897/rmvz.1243

NRC, (National Research Council). (2012). Nutrient Requirements of Swine (11a ed.). National Academies Press. https://www.nap.edu/catalog/13298/nutrientrequirements-of-swine-eleventh-revised-edition

Prada Ospina, R. (2012). Alternativa de aprovechamiento eficiente de residuos biodegradables: El caso de almidón residual derivado de la industrialización de la papa. Revista EAN, ISSN 0120-8160, 180-192. http://www.scielo.org.co/scielo. php?script=sci_arttext\&pid=S0120-81602012000100012

Pulido-Suárez, N. J., Borras-Sandoval, L. M., \& Rodríguez-Molano, C. E. (2016). Elaboración de un alimento energético-proteico para animales, basado en residuos de cosecha de pera (Pyrus communis). Corpoica Ciencia y Tecnologia Agropecuaria, 17(1), 7-16. https://doi.org/10.21930/rcta.vol17_num1_art:455

Rodriguez-Salgado, Angela-Mireya Rodriguez-Molano, Carlos-Eduardo Borras-Sandoval, L. M. (2021). Evaluación de parámetros zootécnicos en terneros suplementados con un alimento fermentado en estado sólido. Biotecnología en el Sector Agropecuario y Agroindustrial, 19(1), 153-166. https://doi.org/10.18684/ bsaa(19)153-166

Saavedra Montañez, G. F., Cala Guerrero, D. C., \& Rodríguez Molano, C. E. (2018). Evaluation of agricultural subproducts submitted to fermentation in a solid state. Revista Bistua, 16(1), 13-27. https://www.researchgate.net/publication/328590249_Evaluacion_de_subproductos_agricolas_sometidos_a_fermentacion_en_estado_solido 
Van Soest, P. J., Robertson, J. B., \& Lewis .B.A. (1991). Methods for dietary fiber, neutral detergent fiber, and nonstarch polysaccharides in relation to animal nutrition. J. Dairy Sci, 74(1), 3583-3597. https://www.journalofdairyscience.org/ article/S0022-0302(91)78551-2/pdf 